ABS-0081 Table 4), iceA (57/91,62.6\%) (Table 7) and iceAl (50/91, 55\%) (IDDF2021-ABS-0081 Table 5), iceA2 (10/91, 11\%) (IDDF2021-ABS-0081 Table 6) strains in patients with gastric cancer. The odds of gastric cancer in $\mathrm{H}$. pylori with iceA was 4.245 higher than those who did not carry iceA (IDDF2021-ABS-0081 Table 7). The odds of gastric cancer in H. pylori with iceA1 was 4.685 higher than those who did not carry iceA1 (IDDF2021-ABS-0081 Table 5).

Conclusions VacA s1, $\mathrm{m} 2$, and iceA are predominant in patients with gastric cancer. As compared with those in non-cancer patients, patients with gastric cancer have less vacA $s 1$ and more $\mathrm{m} 1$ subtypes. The odds of gastric cancer in $\mathrm{H}$. pylori with iceA was 4.245 higher than those who did not carry iceA. The odds of gastric cancer in $\mathrm{H}$. pylori with iceA1 was 4.685 higher than those who did not carry iceA1.

\section{IDDF2021-ABS-0082 APPLICATION AND LEARNING CURVE OF NICE CLASSIFICATION FOR COLORECTAL POLYPS UNDER NON-MAGNIFYING ENDOSCOPY}

XianHua Zhuo*, Yi Lu, Jiachen Sun. Department of Gastrointestinal Endoscopy, The Sixth Affiliated Hospital, Sun Yat-Sen University, China

\subsection{6/gutjnl-2021-IDDF.130}

Background To study the application value of narrow-band image international colorectal endoscopic (NICE) classification under non-magnifying endoscopy in the accuracy of colorectal polyp judgment and clarify the learning curve of NICE classification application of endoscopes with different experiences

Methods 1674 pictures of colorectal polyps from the Sixth Affiliated Hospital of Sun Yat-sen University from December 2019 to April 2020 were collected. Three junior physicians and one senior physician were respectively used for NICE classification. Pathological diagnosis was taken as the gold standard, and the accuracy rate was calculated and the learning curve was drawn

Results The accuracy of NICE classification was $88 \%$ and $95.6 \%$, respectively, for primary and senior physicians. The accuracy rates of primary and senior physicians in the diagnosis of inflammatory hyperplasia and invasive cancer were $87.4 \%$ and $84 \%, 99.2 \%$, and $100 \%$, respectively, with no statistically significant difference $(\mathrm{P}>0.05)$. The accuracy of adenoma and early cancer was $63.2 \%$ and $90.7 \%$, respectively, with a statistically significant difference $(\mathrm{P}<0.05)$ (IDDF2021ABS-0082 Table 1). The Kappa values of the preliminary and senior physicians for the detection of the consistency between NICE typing and pathological results were 0.8 and 0.93, respectively. After 900 and 350 images of colorectal polyps were observed by primary and senior physicians, the accuracy of judgment was nearly $100 \%$ and the fluctuation was reduced (IDDF2021-ABS-0082 Figure 1. Learning curve of NICE for primary and senior doctors)

Conclusions The overall accuracy of NICE classification for colorectal polyps under non-magnifying endoscopy is high, and endoscopists can achieve high accuracy after learning and accumulating a certain number of endoscopic images, which is easy for clinical promotion
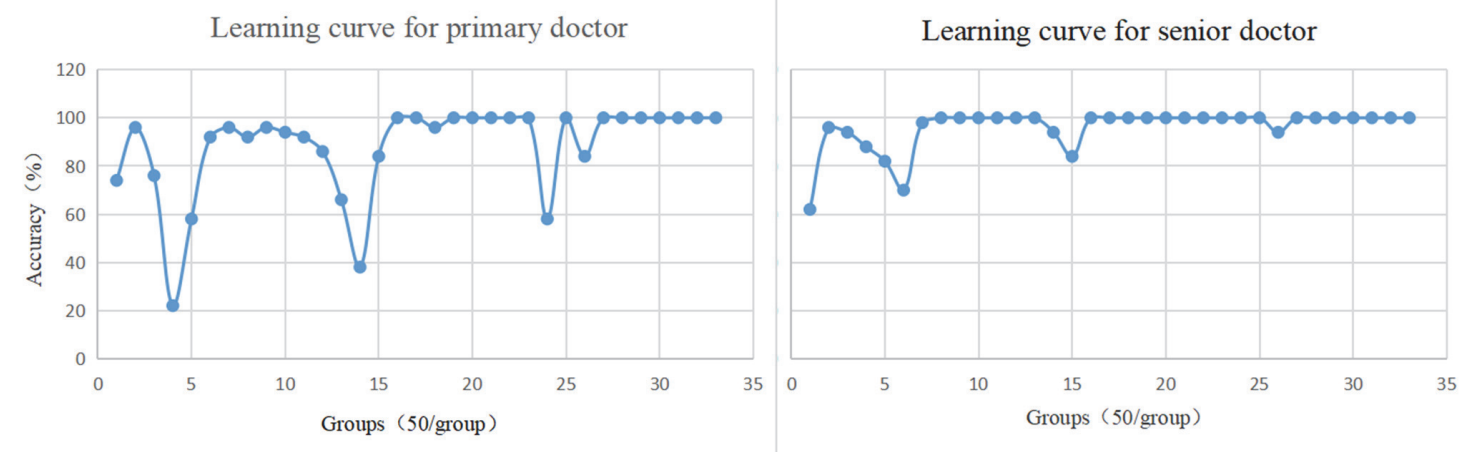

Abstract IDDF2021-ABS-0082 Figure 1

Abstract IDDF2021-ABS-0082 Table 1 Accuracy of NICE for primary and senior doctors

\begin{tabular}{llllllll}
\hline \multicolumn{3}{c}{ Primary doctor } & \multicolumn{5}{c}{ Senior doctor } \\
\hline Type & $\begin{array}{l}\text { Correct } \\
\text { Number }\end{array}$ & $\begin{array}{l}\text { Wrong } \\
\text { number }\end{array}$ & accuracy & $\begin{array}{l}\text { Correct } \\
\text { number }\end{array}$ & $\begin{array}{l}\text { Wrong } \\
\text { number }\end{array}$ & accuracy & $\chi^{2}$ \\
\hline Normal & 933 & 50 & 0.949 & 982 & 1 & 0.999 & 48.332 \\
Type1 & 208 & 30 & 0.874 & 200 & 38 & 0.840 & 1.098 \\
Type2 & 204 & 119 & 0.632 & 293 & 30 & 0.907 & 0.099 \\
Type3 & 129 & 1 & 0.992 & 130 & 0 & 1.000 & $0^{1}$ \\
Total & 1474 & 200 & 0.880 & 1605 & 69 & 0.958 & $1^{1}$ \\
\hline
\end{tabular}

('Pearson's chi-square test; ${ }^{2}$ Continuity correction for chi-square test) 